\title{
Hacia una caracterización del discurso crítico-bibliográfico del siglo XVIII americano*
}

\author{
Cathereen Coltters Illescas \\ Universidad de Concepción \\ ccoltters@udec.cl
}

\begin{abstract}
RESUMEN: El presente estudio ofrece una caracterización del discurso crítico bibliográfico americano, categoría que permite reunir a un heterogéneo grupo de obras que, durante el siglo XviII, intentaron recoger la casi totalidad de la producción cultural de América, en el marco de las polémicas acerca de la inferioridad cultural del Nuevo Mundo; obras producidas por letrados ubicados entre la tradición barroca y la ilustración católica. Este discurso es propuesto, además, como el antecedente del pensamiento crítico literario e historiográfico latinoamericano, y supone una temprana reflexión acerca del estado de la literatura y la cultura ya en tiempos coloniales. Puede decirse, también, que cada repertorio bibliográfico es una evidencia de las diferentes etapas de un discurso crítico bibliográfico en proceso, en el marco de un proceso cultural mayor de autoafirmación del grupo criollo.
\end{abstract}

Palabras clave: discurso crítico bibliográfico; bibliotecas; pensamiento crítico americano.

Aвstract: This study provides a characterization of the American Critical Bibliographic Discourse, a category that brings together a diverse group of works that, in the Eighteenth Century, tried to collect the quasi-totality of the cultural production of America in the time frame of the controversies about the cultural inferiority of the New World, works produced by literates positioned between the Baroque Tradition and Catholic Enlightenment. This speech is also proposed as the antecedent of the Latin American literary and historiographical critical thinking, and is an early reflection on the state of literature and culture in colonial times. It can be also said, that each bibliographic repertoire is evidence of the different stages of a bibliographic critical discourse in the process, as part of a larger cultural process of self-affirmation of the Creole segment.

Keywords: American Critical Bibliographic Discourse; bibliotecas; Latin American Critical Thinking.

FeCha de ReCerción: 13 de agosto de 2015

FeCha de ACEPTACión: 1 de febrero de 2016

* Agradezco el patrocinio y financiamiento brindado por CONICYT/FONDECYT para la realización de cada una de las actividades vinculadas al Proyecto Fondecyt de Iniciación $N^{\circ} 11121278$ : "El discurso crítico-bibliográfico del siglo xviI americano: Relecturas desde el intersticio epistemológico (post) colonial”, proyecto mayor del cual forma parte este trabajo y del que soy investigadora responsable. 
$\mathrm{F}$ el presente estudio abordaremos el discurso crítico bibliográfico una práctica, a un archivo, como a un proyecto criollo - primero- y americanista — después-, mediante el cual se construyó una narrativa fundacional que resultaría en antecedente para la historiografía y la crítica literarias en nuestro continente. Cabe señalar el carácter de proceso de este discurso crítico bibliográfico, en el que se aglutina a un heterogéneo corpus de obras que durante el siglo XVIII intentó recoger la casi totalidad de la producción cultural de la América ${ }^{1}$ prehispánica y colonial; obras elaboradas como respuesta a las polémicas acerca de la inferioridad cultural del Nuevo Mundo, producidas por un sujeto colonial (letrado criollo) ubicado en un espacio epistemológico intersticial, vale decir, en el espacio configurado entre dos epistemes: la tradición barroca y la ilustración católica. El corpus que consideramos bajo la categoría de discurso crítico bibliográfico americano del siglo XviII recoge tanto los textos (catálogos, epítomes, repertorios biobibliográficos, arcas y bibliotecas de papel), como sus metatextos críticohistoriográficos ${ }^{2}$ y los discursos nuncupatorios ${ }^{3}$ que anteceden, en muchos casos, a estas magnas recopilaciones, y en los que se vierten los principios organizativos, evaluativos y las políticas de lecturas delineadas por los bibliógrafos y catalogadores. La tradición bibliográfica de la cultura americana se inicia con el Epitome de la biblioteca oriental i occidental, náutica y geográfica de Antonio de León Pinelo, publicada en Madrid (1629), considerado como el "padre de la bibliografía", y se cierra con la Biblioteca Hispanoamericana septentrional (1816) de José Mariano Beristáin de Souza, texto considerado como el trabajo más logrado y como culminación de una práctica bibliográfica de antigua data en la América septentrional y meridional.

El recorrido que proponemos en estas líneas consiste en una revisión de los aportes de los primeros trabajos que plantearon, en la década de

\footnotetext{
${ }^{1}$ Cabe recordar que el uso del término América ya aparece documentado para 1507.

${ }^{2}$ Walter Mignolo indica que "el metatexto mediante el cual los propios practicantes (e.g. roles institucionales) definen su actividad y los rasgos o propiedades que los textos deben tener para pertenecer a una determinada clase. Las Poéticas, para el caso de la literatura, y los tratados historiográficos (como lo veremos) para el caso de la historiografía, ilustran lo que llamamos metatexto" (1981: 361).

${ }^{3}$ Luis Hachim indica que "se dice de todos aquellos discursos preliminares en que se dedican las obras o se da una función u objeto al texto que se presenta" (2012: 134).
} 
los noventa del siglo xx, la necesidad de elaborar una mirada de conjunto acerca de un posible corpus colonial que, en cuanto reflexión sobre temas y problemas culturales del Nuevo Mundo, podría constituir los tempranos antecedentes del pensamiento crítico-literario americano; luego, ofreceremos una breve exposición de las poéticas coloniales, reflexiones que para los siglos XVI y XVII hicieron consideraciones que ya anuncian un tipo de reflexión sobre los textos producidos en/sobre América que luego se sistematizará en algunos de los géneros/tipos textuales que conforman el discurso crítico bibliográfico; y, por último, ofreceremos nuestra propia propuesta, es decir, la caracterización, propiamente tal, de lo que entendemos como discurso crítico bibliográfico americano.

\section{Primeros estudios de conjunto}

Dentro de la crítica más tradicional referida al tema, pero no por ello menos relevante, se encuentran los estudios pioneros de Joaquín GarcíaIcazbalceta, José Toribio Medina, Agustín Millares Carlo, Ernesto de la Torre Villar y Federico Gómez de Orozco, por nombrar sólo algunos, cuyos aportes fueron indiscutibles contribuciones al estudio de la obra de los bibliógrafos novohispanos y americanos más destacados de los siglos XVII y XVIII. Sin duda, las obras de estos estudiosos contribuyeron enormemente al conocimiento, evaluación y difusión de la labor catalogadora comprendida en los repertorios bibliográficos americanos coloniales, puesto que aquellas obras han servido (y aún sirven) de base a las exploraciones de otros autores latinoamericanistas que revisitaron los repertorios americanos en el marco del advenimiento del V Centenario del "Descubrimiento y Conquista de América" por los europeos. En este sentido, consideramos a aquellos estudios monográficos como un importante punto de partida para la reconstrucción de la historiografía literaria del período y, sin duda, constituyen los esfuerzos fundadores y las primeras sistematizaciones de una reflexión en torno al hecho literario y cultural que deviene en una tradición de pensamiento crítico en nuestro continente.

De modos diversos y con resultados también diversos, la crítica cultural latinoamericana más reciente se ha encargado de explorar las necesarias miradas de conjunto respecto de los repertorios bibliográficos; entre ellos pueden mencionarse los trabajos de Beatriz GonzálezStephan, quien en Fundaciones: Canon, historia y cultura nacional. La 
historiografía literaria del liberalismo hispanoamericano del s. XIX ([1987] 2002), realiza una revisión de la situación colonial respecto de la producción de catálogos y bibliotecas americanos, obras que, a juicio de la autora, contribuyeron a delinear un incipiente proyecto de historiografía literaria ya en los siglos XVII y xVIII. En la "Parte II. La historiografía literaria en Hispanoamérica. 1. La situación colonial. La defensa del Nuevo Mundo: Catálogos y bibliotecas", la autora revisa los antecedentes de dicha práctica y establece los lineamientos de un incipiente espacio letrado colonial.

En el año 1990, Mabel Moraña publica dos artículos titulados "Formación del pensamiento crítico-literario en Hispanoamérica: Época colonial" (1998b) y "Fundación del canon: Hacia una poética de la historia en la Hispanoamérica colonial" (1998c), ${ }^{4}$ textos en los que retoma algunos de los planteamientos de González-Stephan. En el primero de los estudios mencionados analiza los antecedentes inmediatos del surgimiento institucionalizado de la crítica y de la historiografía literaria latinoamericana a la vez que aborda la reflexión criolla acerca de la producción cultural americana. Morańa se pregunta por el sujeto americano y por los "valores estéticos que guían el gusto del sector letrado" reconociendo su "estrecha articulación con el tema de la conciencia y la identidad colonial" (1998: 20). En el segundo de los estudios, la autora indaga acerca de las obras precursoras de la historiografía literaria americana y analiza el rol del letrado criollo como figura secular canonizadora de la práctica cultural letrada, a la vez que explora la apropiación que el letrado americano realiza de las poéticas europeas "en el proceso de formalización de un orden simbólico propio y diferenciado" (21) en el que la práctica letrada resulta ser derivación del paradigma eclesiástico. El proyecto historiográfico de los bibliógrafos, entonces, es visto por Moraña como un "contradiscurso que desmantela los principios del dogma redefiniendo los conceptos de jerarquía y autoridad cultural" (21), con lo cual la sociedad criolla se abriría progresivamente a nuevos contenidos y a nuevos productores culturales. En ambos textos, la autora intenta mostrar la función ideológica que desempeña el letrado colonial como productor cultural.

\footnotetext{
${ }^{4}$ Ambos estudios y el de "Apologías y defensas..." son nuevamente publicados por la autora, en 1998, en Viaje al silencio. Exploraciones del discurso Barroco. Las citas corresponden a esta edición.
} 
En el año 1993, José Anadón edita Ruptura de la conciencia hispanoamericana, obra en la que se incluye el artículo titulado "Sujeto criollo/ conciencia histórica. La historiografía literaria en el periodo colonial" de González-Stephan, en el que se recuperan las ideas propuestas en su libro de 1987 acerca de la relación entre una oligarquía criolla, la emergencia de la conciencia histórica de este grupo y los proyectos culturales como la Bibliotheca mexicana y otros catálogos de este tipo. En el mismo volumen, Nelson Osorio publica "Formación del pensamiento crítico literario en la colonia” (1993), artículo que está muy en sintonía con el anterior y en el que se realiza un recuento tanto de obras del siglo XVII como del XviII que podrían considerarse pioneras, a juicio del autor, del pensamiento crítico-literario que en el siglo XIX dará lugar a las historias de las literaturas nacionales.

Posteriormente, en el año 1994, en su artículo "Apologías y defensas: discursos de la marginalidad en el Barroco hispanoamericano", Mabel Moraña analiza la vinculación entre discursos apologéticos, poéticas en la América colonial e historiografía literaria. Su atención la concentran obras del siglo Xvir en las que es posible advertir asuntos de poética manierista y barroca (1998d: 260); esto la lleva a sostener que "el denominador común en los textos [estudiados] es la celebración de la productividad cultural americana tratando de demostrar a través de la loa, el análisis literario o la simple enumeración de autores y temas poéticos, los méritos culturales y la capacidad crítica del letrado colonial” (261).

En 1995 Antony Higgins publica el artículo "Sobre la construcción del archivo criollo: el Aprilis dialogus y el proyecto de la Bibliotheca mexicana", en el que trabaja en torno a la categoría de archivo criollo para referirse tanto a los textos impresos, como a los productores, a las instituciones, a los códigos socio-culturales, a los modelos y paradigmas con los cuales los letrados criollos escriben. Es decir, el archivo criollo comprende la red de relaciones culturales y el circuito de producción letrada en el que tienen cabida la proliferación de catálogos. Esta categoría propuesta por Higgins resulta fructífera en la medida en que le permite al autor considerar a los catálogos y bibliotecas como piedra angular del archivo criollo. Propone, además, una relectura del contexto en el que se produce la Bibliotheca mexicana de Eguiara y Eguren, cuestión que lo lleva a refutar las lecturas tradicionales que ven en el autor, exclusivamente, a un precursor del nacionalismo mexicano. Más tarde, en el año 1996, en su artículo "La 'Bibliotheca mexicana': Hacia una 
poética de la legitimidad criolla", Higgins retoma algunos de los planteamientos sobre la obra de Eguiara y Eguren contenidos en su trabajo anterior, con el fin de mostrar la autonomía intelectual y cultural criolla. En este sentido, coincide con algunas ideas de Moraña respecto de la articulación de la biblioteca como parte de un proyecto de búsqueda de legitimación discursiva. Cuestiones similares son las que retoma posteriormente en su estudio "La construcción del archivo criollo: Temas de los conocimientos en la Biblioteca mexicana y la Rusticatio mexicana" (2000), en el que Higgins indaga acerca de la vinculación que existe entre conocimiento y poder en la práctica letrada de los criollos de Nueva España y Guatemala en el siglo XviıI. El autor analiza el modo en que los criollos letrados elaboraron un corpus de conocimiento, es decir, un archivo con el fin de establecer su autonomía intelectual dentro de las estructuras administrativas de la España colonial. Esta vez incluye en su análisis las obras de Juan José Eguiara y Eguren y Rafael Landívar, ambas escritas en latín.

Para el año 2000, Luis Hachim publica Tres estudios sobre el pensamiento crítico de la ilustración americana, tres ensayos en los que analiza el pensamiento crítico literario distinto del siglo XviII. En el primero de ellos titulado "La carta a los españoles americanos (1791) del Abate Viscardo y la tradición crítica en América” aborda la manera en que el Abate Viscardo "asume el pensamiento del criollo y su problemática" (2000a: 20) frente a la estructura administrativo-burocrática del poder colonial. En el segundo ensayo, "Políticas de identidad y pensamiento americano en una Biblioteca del siglo xvıI", Hachim estudia las estrategias de identidad criolla elaboradas por los catalogadores y en especial las que emplea José Mariano Beristáin de Souza, cuestión que lo lleva a sostener que "es patente la preocupación crítico-literaria que en función de un pensamiento diferenciado, se hace cargo de la identidad" (2000b: 48). En el tercer ensayo, "La Ilustración en Eugenio de Santa Cruz y Espejo" (2000c) analiza la construcción de un locus de enunciación cultural propio en la obra de un pensador ilustrado, contribuyendo a delinear el pensamiento crítico latinoamericano distinto. Esta última categoría la empleará en el artículo "De León Pinelo..." (2001). En el estudio "Teorías hegemónicas y pensamiento excluido. El caso de Beristáin de Souza" (1999), Hachim estudia la Biblioteca Hispanoamericana Septentrional como un repertorio que recoge tanto la producción letrada criolla como la indígena. En este texto aborda además los problemas 
que generan el estudio de este tipo de corpus cuando se les analiza desde la óptica de paradigmas de interpretación "universalistas", interpelando de paso a las teorías hegemónicas que escamotean su incorporación a la tradición de pensamiento crítico-literario latinoamericano. Hachim publica, además, otros trabajos relativos a las bibliotecas del siglo xviII. En el artículo titulado "De León Pinelo a Beristáin: Ensayo sobre la tradición de los repertorios literarios latinoamericanos” (2001), el autor se propone caracterizar la figura del autor/bibliógrafo que enuncia los prólogos presentes en gran parte de los repertorios bibliográficos elaborados desde el siglo xviI al xviII, entre ellos los de León Pinelo, Boturini, Eguiara y Eguren, Llano Zapata, Navarrete, Alcedo y Bejarano y, por último, Bersitáin de Souza. Por último, en el artículo "Esbozo de una narrativa del pensamiento crítico y literario en el período colonial" (2009), Luis Hachim propone un análisis y un registro de obras que en el período colonial evidencian la temprana formación de un pensamiento crítico-literario, narrativas que, a su juicio, profundizan la memoria y reconstruyen el discurso historiográfico desde lugares otros. Posteriormente, en el año 2002, Luis Hachim presenta su tesis doctoral La Biblioteca Hispanoamericana Septentrional de José Mariano Beristáin de Souza. Una práctica bibliográfica en la Ilustración hispanoamericana; texto que publicará, en el año 2012, bajo el título de Summa de libros y autores del periodo colonial. La Biblioteca Hispanoamericana de José Mariano Beristáin de Souza; en él se recogen muchos de los planteamientos contenidos en los artículos anteriores y, además, se revisan los diferentes repertorios bibliográficos del XVII y del xviII; se definen y conceptualizan los diferentes géneros en los que se recopilan las obras del período; se esboza brevemente el discurso bibliográfico y se estudian algunas categorías; pero, sobre todo, se realiza un acucioso estudio de la Biblioteca Hispanoamericana de Beristáin de Souza, obra que es considerada por el estudioso como el repertorio cúlmine del siglo Xviı y la biblioteca más completa publicada hasta ese momento. Cabe señalar que en este valioso estudio, Hachim proyecta sus reflexiones desde los repertorios americanos hasta la práctica bibliográfica del siglo XIX, es decir, las bibliotecas nacionales, con lo cual abarca un amplísimo espectro de la práctica catalogadora americana. Sin duda, un arduo esfuerzo que supone, a nuestro juicio, el primer trabajo que realmente aporta una mirada de conjunto o, al menos, una visión general de la producción bibliográfica desde su temprana aparición en el siglo XVII hasta el siglo XIX. 
Cabe destacar, además, que los críticos y estudiosos arriba mencionados comparten una perspectiva de lectura revisionista que, como indicábamos, plantea la necesidad de estudios de conjunto con el fin de rescatar la idea de proceso en la conformación de esta tradición críticobibliográfica. Además, la perspectiva de lectura que proponen intenta visibilizar la importancia cultural e ideológica de este corpus para la construcción de una subjetividad criolla emergente, que reflexiona sobre el patrimonio cultural propio y el heredado de las comunidades prehispánicas; esto con el fin de disputar un lugar cultural en el mapa intelectual, primero, frente a Espańa y Europa, y luego, como base para una autonomía cultural. Es por ello que no debe perderse de vista la relación dialógica (Métropli/Colonia), es decir, transatlántica (si se prefiere) como marco en el que estas obras son producidas, porque lo que está en juego aquí es el poder representacional del Nuevo Mundo y la legitimidad de los discursos sobre esta nueva realidad. Lo anterior ha abierto la puerta para reinterpretar y/o completar, cuando no refutar, algunos planteamientos con los cuales la crítica tradicional había analizado los intereses que motivaron a los letrados criollos compiladores de bibliotecas y catalogaciones. Por último, para dichos autores los repertorios bibliográficos americanos constituyen los antecedentes de la formación del pensamiento crítico-literario hispanoamericano (Moraña y Osorio), de la historia de la crítica literaria en la sociedad colonial (Osorio), de la historia e historiografía literaria americana (González-Stephan) y del pensamiento americano distinto (Hachim).

En diálogo con los estudios anteriores, el aporte de nuestro trabajo radica en caracterizar la práctica catalogadora y visibilizar sus condiciones culturales, atendiendo a esa mirada de conjunto que sugieren los estudios modelos. Desde nuestra perspectiva el discurso crítico bibliográfico comprende una práctica, un archivo y un proyecto identitario ${ }^{5}$ del sector letrado criollo, en proceso, como habría quedado sugerido en algunos de los trabajos críticos reseñados, y que tendría su propia singularidad en el siglo XvIII, distinta respecto de la centuria anterior, por ejemplo. Esto último nos permite indagar y proponer una serie de elementos, preocupaciones y búsquedas existentes en los repertorios de los letrados americanos de dicho siglo.

${ }^{5}$ Recogemos esta idea de Luis Hachim, pero la desarrollamos de modo diferente. Ver infra. 
LOS DESLINDES: POÉTICAS COLONIALES

Así como las historias literarias y también la historiografía de la literatura del XIX comparten puntos de reflexión con el discurso crítico bibliográfico, las poéticas coloniales (XVI y XVII) constituyen otro género especial que se emparenta, indirectamente, con los catálogos, epítomes y/o bibliotecas de papel, por cuanto establecen teorías generales sobre la escritura y reflexionan acerca de la práctica literaria; ${ }^{6}$ reflexiones que, en el caso de los repertorios bibliográficos, aparecen entremezcladas con el inventario de nombres y con el comentario de textos sin constituir todavía una materia totalmente separada. Las poéticas coloniales coexistirían con los repertorios bibliográficos, pero se diferencian de estos últimos en que no pretenden ser compilaciones totalizadoras de la producción cultural; surgen en un contexto diferente al de las polémicas que dan origen a muchas de las bibliotecas de los siglos XVII o XVIII (aunque hay excepciones como el conocido caso de Espinosa Medrano), mientras que las poéticas coloniales son adaptaciones de las europeas, cuyo afán es orientar el proceso de producción americano ajustándolo a patrones reconocibles y vigentes para el lector europeo, y en el que el comentario del contenido de los textos es lo central del ejercicio crítico, a diferencia de los repertorios bibliográficos donde el comentario tiene un lugar — cuando lo hay - como parte de la notitia rei literariae. Por lo tanto, las póeticas y las bibliotecas difieren también en su función cultural.

En el año 1995, Francisco Javier Cevallos publica el artículo "Imitatio, aemulatio, elocutio: Hacia una tipología de las poéticas de la época colonial", en el que reúne y tipifica un cierto número de textos claves para/del pensamiento crítico latinoamericano, los que constituyen una temprana muestra del modo en que tomó forma la reflexión teórica acerca de la composición de los textos y escritos coloniales. Se trata aquí de la adaptación e implantación americana de poéticas provenientes de la "teoría

\footnotetext{
${ }^{6}$ Se han considerado como hitos de este primer discurso valorativo de la literatura para el siglo Xvir el Discurso en loor de la poesía de una poetisa anónima (1608), "Epístola a Belardo" de Amarilis, Triumpho Parthénico (1683) de Carlos de Sigüenza y Góngora, Apologético en favor de don Luis de Góngora (1662) del cusqueño Juan de Espinosa Medrano (el Lunarejo), Grandeza Mexicana (1604) y Compendio apologético en alabanza de la poesía (1604) del mexicano Bernardo de Balbuena.
} 
literaria española”; opinión similar a la de Mabel Moraña (1998c), para quien las poéticas coloniales son poéticas europeas en América.

El estudio de Cevallos comienza bosquejando brevemente el problema general de las teorías sobre la escritura durante el Renacimiento, fondo, según el autor, sobre el que se escriben las teorías coloniales. Indica que ya el humanista Juan Luis Vives postulaba que el arte tenía una teoría propia, abstracta, que no correspondería necesariamente en su perfección a los modelos de la Antigüedad.

El acto de escribir, el imitar que toda creación artística supone, se libera de los modelos preexistentes, puesto que la ciencia (retórica, poética) que determina tal acto tiene sus propias leyes, inspiradas en la naturaleza y no en los modelos retóricos. Es decir, el poeta es libre de crear no sólo porque los tiempos han cambiado (justificación tradicional en favor de los "modernos"), sino porque la teoría es muchísimo más amplia que lo que los "antiguos" habían pensado (502).

Cevallos divide las poéticas del siglo XviI en tres núcleos: imitatio, aemulatio y elocutio (503): a) La imitatio, considerada por Aristóteles como el aspecto fundamental de la creación literaria, sirve a Cevallos para agrupar textos cuya preocupación es la composición de la poesía y su función social; es decir, qué se debe imitar, punto que será tema de polémicas durante la época y criterio base para la distinción entre historia y poesía. Los textos incluidos seguirían fielmente los modelos retóricos europeos, según indica, y deberían defender el acto de creación poética mediante argumentos morales; éstos son: el Discurso en loor de la poesía (1608) de la poeta peruana anónima "Clarinda" y el Compendio apologético en loor de la poesía $(1604)^{7}$ de Bernardo de Balbuena, quien sería en su opinión el primer gran teórico de las letras hispanoamericanas. b) La aemulatio ya no constituye únicamente apologías de la poesía, sino que, a juicio de Cevallos, incluye tratados que resultan ser verdaderas praxis críticas. Su propósito es "mejorar a los antiguos, y demostrarlo científicamente mediante comentarios extensos de la obra de los modernos" (503), razón por la que se estudian filológicamente las obras y, según Cevallos, "a veces con un rigor insospechado" (503). Incluye en este grupo el "Prólogo" a la Grandeza Mexicana (1604) de Bernardo de Balbuena, el primer crítico, en sentido moderno, de las le-

\footnotetext{
${ }^{7}$ Texto incluido en la Grandeza Mexicana.
} 
tras hispanoamericanas, ${ }^{8}$ quien hace un comentario a su propio trabajo; Cevallos incluye, además, a Juan de Espinosa Medrano y su Apologético en favor de Don Luis de Góngora (1662). c) La elocutio considera textos de preceptiva literaria o retórica que circularon en colegios y universidades coloniales, y todas aquellas obras que presentan reglas de escritura para la producción de obras originales. Nuevamente, Cevallos incluye a Bernardo de Balbuena con el "Prólogo" a su Bernardo, breve compendio sobre teoría de la poesía épica, como indica; incluye, además, el Artis Poeticae. Compendium (editado en 1884 por Luis Cordero con traducción castellana) del jesuita Joaquín Ayllón, libro de texto ocupado en los colegios de la Compañía de Jesús; y, por último, La Thomasiada del dominico Diego Sáenz de Ovecuri, publicada en Guatemala en 1667 y, a decir de Cevallos, "la poética y retórica más original que se escribió en la colonia, y hasta donde sepamos, las más ambiciosa y original de las letras hispanas" (503). Finalmente, Cevallos sostiene que en la "teoría literaria de la época" se expone otro problema original: "la aparición del lector (espectador) como integrante fundamental del acto de la creación literaria" (502), fenómeno que tendría lugar con el surgimiento de la burguesía como clase dominante de la vida europea: "éste es ya un público ciudadano, que se va refinando paulatinamente". El artista crearía para un público que "consume" el arte, y la obra artística "deja de perseguir un ideal de belleza o perfección y se orienta a deleitar más que a enseñar, en inversión novedosa del postulado horaciano" (502). Éstos serían, en opinión del crítico, los dos cambios innovadores de la teoría poética española de la época.

\section{PARA UNA CARACTERIZACiÓN DEL DisCURSO CRÍTICO BIBLIOGRÁFICO AMERICANO DEL SIGLO XVIII}

Durante el siglo XviII, los agentes de la cultura escrita euroamericana, vale decir, los letrados pertenecientes a la élite criolla, compusieron obras de muy diversa factura genérica (catálogos, arcas, epítomes, re-

\footnotetext{
${ }^{8}$ Respecto a esta última apreciación, Alberto Zum Felde, Mabel Moraña, Ángel Rama, Antonio Cornejo Polar, Hernán Vidal, Raquel Chang-Rodríguez y Nelson Osorio coinciden en reconocer al Apologético como el texto que funda la crítica literaria en Hispanoamérica y a su autor, Espinosa Medrano (El Lunarejo) como el primer crítico literario de la zona meridional, propiamente tal.
} 
pertorios bio-bibliográficos y bibliotecas de papel), ${ }^{9}$ en las cuales intentaron condensar la totalidad del acervo patrimonial correspondiente a la producción intelectual y cultural del Nuevo Mundo. Estas vastas recopilaciones bibliográficas conforman un corpus de obras sumamente heterogéneo no sólo desde el punto de vista genérico sino también por su contenido, respondiendo así a proyectos ideológicos, políticos y culturales de índole diversa; no obstante, se inscriben siempre dentro de la vertiente hegemónica de la cultura letrada, por cuanto fueron elaborados en la lengua, los registros, los modelos y los géneros vigentes de la cultura metropolitana en contacto con América. En este sentido, los repertorios bibliográficos son portadores de una visión euroamericana que, no por ello, cancela su tensa relación con otras visiones subalternas del mundo colonial a las que subsume como parte del archivo criollo (Higgins) con el propósito de construir un puente entre pasado y presente, y como modo de ingresar en la historia. Así, tenemos que los repertorios bibliográficos son síntomas y manifestaciones de los distintos momentos de la implantación de la cultura letrada en América y evidencian las diferentes etapas de un pensamiento crítico en proceso de definición/diferenciación, a la vez que delinean las huellas del proceso literario que se iniciara con la Conquista española en su contacto con las culturas originarias.

En el estudio Summa de libros y autores del periodo colonial (2012), Luis Hachim comenta que

las prácticas que implican las bibliotecas, desde el momento de su constitución en Hispanoamérica, nos refieren no sólo a la resistencia frente a la pretendida precariedad cultural, social y política de los americanos —en la visión de los europeos—-, sino también a una epistemología situada en perspectiva de la diferenciación y el trabajo con la diferencia (2012: 131).

\footnotetext{
${ }^{9}$ Respecto del corpus que hemos venido refiriendo - y en el que la mayor parte de los estudiosos coincide-, se compone de la Biblioteca Mexicana (1755) de José Eguiara y Eguren; las Memorias histórico-filosóficas, crítico-apologéticas de la América Meridional (1758) y el Epitome cronológico o idea general del Perú (1776) y la Carta persuasiva al Señor Don Ignacio de Escandón sobre Assunto de Escribir la Historia-Literaria de la América Meridional (1768) de José Eusebio Llano Zapata; la Biblioteca Americana. Catálogo de Autores que han escrito de la América en diferentes idiomas y noticia de su vida y patria, años en que vivieron, y obras que escribieron (1791) de Antonio de Alcedo y Bejarano; El Nuevo Luciano de Quito o Despertador de los ingenios (1779) y La ciencia blancardina (1780) de Francisco Javier Eugenio Santa Cruz y Espejo; Arca de Letras y Teatro Universal (1780-1811) de Juan Antonio Navarrete, y la Biblioteca Hispanoamericana Septentrional (1816) de José Mariano Beristáin de Souza.
} 
$\mathrm{Al}$ respecto, Beatriz González-Stephan, en Fundaciones: canon, historia y cultura nacional (2002), sostiene que los catálogos y los "diversos trabajos bibliográficos o de interpretación histórica de la cultura en la América Hispana, de acuerdo al tipo de literatura que seleccionen y el pasado que reconstruyan, representan variables ideológicas que corresponden, a su vez, a los diferentes proyectos político-sociales de las élites históricamente dominantes" (87). Estas variables darían lugar, según la autora, a dos posibilidades interpretativas de aquello que venimos designando como discurso crítico bibliográfico americano: la primera de ellas circunscrita en una perspectiva más eurocentrista que defendió y celebró la cultura europea en el Nuevo Mundo, es decir, reprodujo los patrones culturales metropolitanos en un contexto social nuevo, lo que significó la "legitimación absoluta de sus valores, además de refutar el argumento que constreñía la cultura europea sólo a tierras también europeas" (88), generando con ello "una transculturación de los campos de producción intelectual y, por consiguiente, la habilitación de formas discursivas occidentales cuya originalidad se disparó en situaciones de periferia colonial" (88). Más tarde, la autora señala que el carácter de los repertorios bibliográficos americanos los definió como prácticas celebratorias del poder metropolitano $\mathrm{y}$, a la vez, como prácticas que enmascararon la decadencia del mismo, actitud que reconocemos como típicamente barroca. Por ello agrega:

De allí pareciera que el trabajo de catalogación bibliográfica estuviera en estrecha relación con una perspectiva ideológica, que al enumerar la riqueza cultural y literaria del Nuevo Mundo, traspuso a nivel discursivo lo que se ha llamado "cornucopia" americana. Es decir, que también los catálogos y los epítomes — sobre todo en el siglo xvir cuando empezaron a surgir - fueron formas discursivas que, sin dejar de cumplir su función pertinente, produjeron un efecto ideológico homólogo a toda una retórica, que para la época sustentaba la grandeza y la magnificencia del imperio español. Y de manera particular, fueron la contrapartida en tanto prácticas ideológicas de una situación de inminente decadencia del poderío español (88; las cursivas son nuestras).

No hay que olvidar, sin embargo, que la mayor parte de la producción de repertorios bibliográficos del siglo xviII se enmarca dentro de un proyecto americanista que busca impugnar/refutar las teorías ilustradas anti-americanistas que sostienen la inferioridad de nuestro con- 
tinente (De Paw, Buffon y Robertson), aspecto que ha llevado a ver en esta actitud los primeros lineamientos del patriotismo criollo. El caso de Beristáin de Souza, a diferencia de los demás repertorios, resulta complejo en este sentido porque se aleja de esa intención y se inscribe, más bien, dentro de un proyecto legitimista de evidentes simpatías monárquicas (cfr. Hachim 2012).

Según González-Stephan, los repertorios bibliográficos, al reivindicar el uso del latín y el español como las lenguas literarias y al excluir las referencias a las culturas indígenas, reforzaron la hegemonía hispana y la cultura escrita, proyectando en el dominio de las letras una idea de "estabilidad" de la sociedad colonial (2002: 89). El uso del latín en los repertorios del siglo XVII —excepto el Epitome de León Pinelo que no fue escrito en esta lingua franca-, supuso una consecuencia ideológica que "implicaba la cancelación del pasado y de las culturas indígenas, la exclusión de las manifestaciones orales y otras formas de codificación escrita, y el reconocimiento del libro impreso en tanto marca de prestigio cultural y como signo de trascendencia histórica” (90).

La segunda vertiente, vinculada no sólo a la defensa de la cultura en el Nuevo Mundo sino, más propiamente, de la cultura americana, encaminó, según González-Stephan, sus esfuerzos a la reconstrucción y valorización del pasado indígena como "el sustrato cultural más antiguo sobre el cual se cimentó la civilización española" (91). Esta recuperación del pasado indígena tenía lugar desde el siglo XVI, no obstante, el trabajo de Eguiara y Eguren sería el que marcaría, en el siglo XviII, una nueva orientación crítica y metodológica, como comenta la autora. La operación ideológica en cuestión, aquí, consistió en que los letrados criollos pusieron "las raíces en la antigüedad prehispánica" para aparecer "dentro de los muros de su ciudad letrada como herederos simbólicos de las culturas indígenas" (91-92). Es decir, la recuperación del pasado indígena por parte de los criollos es política, antes que científica (Florescano citado por González-Stephan: 92), y se llevó a cabo con el fin de otorgar mayor "espesor histórico" a la realidad que se fundaba como presente y anclaje:

Por ello, su perspectiva histórica prospectiva les llevó a replantearse una a otra el pasado y colocar sus raíces en la antigüedad prehispánica. Así, la originalidad cultural de estos sectores sería de momento deudora de un pasado que había sido excluido de los catálogos y bibliotecas del siglo 
anterior, y les permitiría sólo retóricamente y sin mayores compromisos autentificar su diferencia étnico-cultural con los hispanos peninsulares (92).

Siguiendo a Mariano Picón-Salas, la crítica Beatriz González-Stephan indica que los viajeros y los hombres de "ciencias" (los letrados) fueron los agentes encargados de desmentir con sus obras, imbuidas del nuevo espíritu racionalista de la Ilustración, las falacias y prejuicios europeos sobre el mundo americano. En su opinión, esta conciencia histórica atravesaría todos los sectores sociales, pero "sólo los blancos criollos letrados proyectaron en su cultura ilustrada una comprensión sistemática de su realidad" (93). Refiriéndose a las consecuencias epistémicas de la práctica bibliográfica, la autora agrega que "la importancia de esto reside en que por primera vez la realidad cultural es pensada como proceso; se diseñan sus etapas, considerándose cada una de ellas históricamente necesarias y no cualitativamente despreciables" (1993: 31; las cursivas son nuestras).

En la recopilación Viaje al silencio (1998), Mabel Moraña apuntaba también hacia la necesidad del estudio del texto colonial desde una perspectiva de proceso que diera cuenta de su dinámica transformadora; idea que recogemos y que nos ha permitido considerar a la práctica bibliográfica catalogadora como un verdadero proceso en el que los catálogos y las bibliotecas son en sí las huellas de la conformación de una conciencia americana en progresiva diferenciación y son, también, las huellas del proceso de conformación de lo que — por extensión del término- llamaremos "sistema literario". Cada repertorio bibliográfico resulta ser una evidencia de las diferentes etapas de dicho proceso cultural, epistémico e identitario liderado por los letrados criollos en una relación dialógica con la metrópoli, que va teniendo lugar en la transición que va desde el agotamiento de las tradiciones del Barroco — aun cuando persistan algunas de sus modalidades - y la implantación de las diferentes manifestaciones de la Ilustración católica ${ }^{10}$ y/o humanista en

\footnotetext{
${ }^{10}$ Respecto de esta lenta transformación que va desde el paradigma barroco al ilustrado, Antonio Rubial indica que "en los discursos generados a lo largo del siglo xviII podemos observar un cambio paulatino de la percepción barroca, marcada aún fuertemente por los temas religiosos, hacia la concepción ilustrada, que sin abandonar el cristianismo se interesaban también por temas laicos como los de la ciencia y la tecnología.
} 
América, lo que queda evidenciado en las particularidades que asume la práctica en el caso de cada catalogador. En este sentido, concordamos con Morańa cuando apunta a que la práctica bibliográfica,

más que proyectos de relevamiento y catalogación, [son] verdaderas construcciones histórico literarias que se interrogan sobre el lugar de América, su articulación a la tradición occidental y sus aportes al pensamiento universal. Pero sobre todo son testimonios de una indagación identitaria que el letrado criollo, al concebirse como sujeto de su propia historia, emprende como forma de redefinir el origen y el futuro de las sociedades americanas (1998: 20).

A propósito de las diferencias observadas entre las bibliotecas de Eguiara y Eguren y Beristáin de Souza, Hachim indica que ambos proyectos corresponderían a modalidades distintas del espíritu criollo, es decir, cada biblioteca representaría variantes al interior del "proyecto del pensamiento hispanoamericano" (2012: 153); suscribimos esta idea del estudioso chileno, pero agregamos, además, que cada catálogo/ repertorio bibliográfico constituiría una etapa diferente en la evolución del pensamiento crítico americano, mostrando de paso las formas de concreción que fue tomando el proyecto de identidad criolla y reflejando las distintas versiones del patriotismo criollo. Insistimos, nuevamente, en la idea de concebir a los repertorios bibliográficos como un discurso crítico bibliográfico en proceso, por cuanto cada catálogo o biblioteca mostraría también las diferentes etapas de maduración del mismo, en el marco de un proceso cultural mayor de autoafirmación del segmento criollo; ejemplo de lo anterior son los trabajos de Eguiara y Eguren, quien introduce métodos y formas ya modernas de catalogación, o el de Llano Zapata, que comprende tempranamente la necesidad de elaborar una "historia de la literatura", o el del propio Beristáin de Souza, quien "mejora" y actualiza el método empleado por su antecesor Eguiara; sirvan de ejemplo también las conversaciones de Santa Cruz y Espejo en las que ácidamente delinea nuevos públicos lectores y amplía los circuitos

Sin embargo, ese cambio es perceptible sólo entre algunos sectores de la élite que tenían acceso a la educación ilustrada [...]. En la mayor parte del territorio predominaba una cultura de oralidad en la cual la exuberante propuesta del Barroco había arraigado profundamente. En esos ámbitos los cambios propuestos por la Ilustración no tuvieron ningún efecto" (347). 
de producción letrada, o el caso de Juan de Navarrete, quien escribe para "sí mismo" aun cuando se dirija a un "lector curioso", o, el de Alcedo y Bejarano, cuyo sujeto discursivo corresponde ya al de un sujeto ilustrado moderno. $^{11}$

En la Summa (2012), Luis Hachim se refiere brevemente al "discurso bibliográfico" distinguiendo entre dos de las acepciones del término Bibliotheca: la topográfica institucional y espacial del término (depósito que reúne libros y documentos, primera acepción moderna) (132) y la textual o discursiva (un libro que agrupaba a un conjunto o recopilación de obras y autores de un país determinado) (133). En palabras del autor, es esta segunda acepción registrada en los diccionarios la que enmarca específicamente a este tipo de repertorios dentro de la tradición del texto bibliográfico en Hispanoamérica. Para Hachim, las bibliotecas poseen un afán totalizador que no puede ser reducido únicamente al movimiento enciclopedista enunciado por Diderot en el siglo XVIII (131), por cuanto su carácter compilatorio estaría dado por su carácter de metalibro que se propone recoger la monumentalidad y exuberancia de la vida cultural americana.

En lo que nos concierne, proponemos designar como discurso crítico bibliográfico tanto a los textos o metalibros (aparatos/repertorios bibliográficos) como a las prácticas (reflexión crítico-literaria-historiográfica que organiza, articula y evalúa la producción cultural de la América hispana) como al proyecto identitario (consolidación de una conciencia sectorial) que se corresponde con el proceso de autoafirmación de la autonomía del sujeto social criollo y del mundo americano. Conside-

${ }^{11}$ En estas líneas ofrecemos, únicamente, una mirada general o de conjunto de los repertorios bibliográficos; no obstante, se incluirá un examen más detallado de los mismos y de sus aportes en otro estudio que está en preparación. Los repertorios estudiados son: Memorias histórico-filosóficas, crítico-apologéticas de la América Meridional (1758) del peruano José Eusebio Llano Zapata, Biblioteca Mexicana (1755) del mexicano de ascendencia vasca Juan José de Eguiara y Eguren, El Nuevo Luciano de Quito o Despertador de los ingenios (1779) y La ciencia blancardina (1780) de Francisco Javier Eugenio de Santa Cruz y Espejo, médico y cirujano mestizo, la Carta persuasiva al Señor Don Ignacio de Escandón sobre Assunto de Escribir la Historia-Literaria de la América Meridional (1768) de José Eusebio de Llano Zapata, Biblioteca Americana. Catálogo de Autores que han escrito de la América en diferentes idiomas y noticia de su vida y patria, años en que vivieron, y obras que escribieron (1791) del ecuatoriano Antonio de Alcedo y Bejarano y, por último, Biblioteca Hispanoamericana Septentrional (1816 los dos primeros tomos, el tercero en 1821) del mexicano José Mariano Beristáin de Souza. 
ramos dentro de esta categoría a la extensa producción bibliográfica producida entre los siglos XVII y XVIII, no obstante, nos ocuparemos específicamente de la producción del siglo XviII por constituir un momento en el que los repertorios definen con mayor claridad un proyecto americanista y un antecedente del patriotismo criollo. Entonces, tenemos que la expresión discurso crítico bibliográfico americano apunta también a las siguientes funciones, es decir, nos resulta útil: ${ }^{12}$

1. Para señalar/enfatizar que estamos en presencia tanto de una práctica como de un archivo cultural (Hachim 2012: 60), pero también de un proyecto (152), según adelantamos en líneas anteriores: como práctica porque el letrado americano recopila, selecciona, ordena, clasifica y evalúa afanosamente la (casi) totalidad de la producción cultural americana elaborada en/sobre el Nuevo Mundo por letrados con algún tipo de residencia en estas tierras; como $\operatorname{archivo}^{13}$ porque supone la conservación del patrimonio y el rescate de la herencia cultural del nuevo sujeto hispanoamericano, patrimonio y herencia que pueden abarcar desde el pasado indígena hasta el presente del compilador; como proyecto porque supone la comprensión de la emergencia de una conciencia histórica y estamental, la del criollo, en la que se definen las variantes de un pensamiento americano en formación, por lo que dicho proyecto resulta, entonces, en una triple búsqueda identitaria, de autoridad discursiva y autorrepresentativa de lo propio.

2. Para distinguirla de las historias literarias del liberalismo, ya que el lugar epistemológico y cultural desde donde se elaboran/enuncian los repertorios bibliográficos corresponde a la transición entre el agotamiento del Barroco americano y el advenimiento de una Ilustración de cuño católico (Góngora), en ningún caso homologables completamente ni al Barroco ni a la Ilustración europeas. El marco ilustrado americano, telón de fondo sobre el cual serán elaborados buena parte de los catálogos revisados, recoge las ideas de intelectuales como el español Feijoó para

${ }^{12}$ Una versión abreviada de estas distinciones-funciones fue incluida en el estudio "Notas para una cartografía de la ciudad letrada: las historias literarias y las Bibliothecas de Eguiara y Eguren y Beristáin de Souza", a ser publicado en Historia de las Literaturas en México, proyecto del Instituto de Investigaciones Filológicas de la UNAM, volumen I, coord. Dra. Esther Martínez Luna.

${ }^{13}$ Cabe señalar que esta idea de archivo es original de Anthony Higgins, y la utilizamos en el sentido que él propone en los estudios consignados en la bibliografía general (cfr. Higgins 1996 y 1995). 
refutar el antiamericanismo vigente en algunas versiones europeas de la Ilustración que promueven la inferioridad americana; se nutre, además, de las distintas etapas del humanismo jesuítico (Roig); permite la convivencia entre elementos escolásticos y la razón ilustrada (fe/razón), y convive en él la resistencia al peripatetismo, todo lo anterior matizado por el tamiz del catolicismo hispano. Por otra parte, los repertorios bibliográficos resultan ser el primer antecedente de las historias de las literaturas nacionales y de las bibliotecas nacionales. El discurso crítico bibliográfico americano del XVIII, en este sentido, comprende esfuerzos críticos que continúan la labor catalogadora comenzada tempranamente en el xviI, pero se distingue de ella ya que presenta una formalización menos estática de la realidad que describe. Por su parte, la historiografía literaria corresponde a una reflexión crítica que acompaña y describe los productos culturales del liberalismo (siglo xIx) y (González-Stephan 1993 y 2002) define el canon en torno a la noción de literatura nacional vinculada al nacimiento de los estados nacionales hispanoamericanos. Entonces, tenemos que discurso crítico e historias literarias no son categorías homologables, puesto que responden a concepciones de la historia literaria y del quehacer letrado diferentes en cada momento.

3. Para indicar que el discurso crítico-bibliográfico no constituye un género diferenciado y definido, sino que bajo esa denominación incluimos a varias modalidades genéricas mediante las cuales se catalogó y recopiló la historia cultural americana producida entre los siglos XVI al XviII, generando un discurso crítico que hoy, por extensión del término, podemos emparentar con el de las historias literarias debido a la similitud entre sus criterios y principios operativos. En los siglos XVII y XVIII las poéticas (Cevallos 1995) y las historias naturales y civiles (Peralta 2006) ${ }^{14}$ fueron algunas de las modalidades genéricas que organizaron y explicaron la reflexión sobre el texto colonial, por ejemplo.

4. Por último, para indicar que el discurso crítico-bibliográfico reúne, además, tanto crítica como historia literaria, ya que si recordamos

${ }^{14}$ En el apartado anterior referimos la clasificación de las poéticas coloniales según Cevallos. Para el caso de las historias naturales y civiles, Peralta Ruiz estudia tres obras de la América Meridional, el Epitome cronológico o idea del Perú (1776) de José Eusebio Llano Zapata; la Historia del reino de Quito en la América Meridional (1789-1792) del jesuita quiteño Juan de Velasco y el Compendio de la historia geográfica, natural y civil del reino de Chile (1788-1795) del jesuita chileno Juan Ignacio Molina. 
las advertencias de González-Stephan, corresponde a un continuum indiferenciado, al que se suman tanto las noticias literarias (notitia rei literariae) ${ }^{15}$ como las noticias bibliográficas (notitia librorum).

En este sentido, el estudio de los discursos nuncupatorios y de los metatextos historiográficos presentes en estas obras reveló la presencia de ciertas constantes y de elementos comunes que nos han permitido considerar la catalogación como una práctica reflexiva en la que tienen lugar, además, las siguientes operaciones letradas criollas: a) se indaga acerca de las condiciones en las que el letrado americano produce saberes, b) se delinea y legitima un lugar de enunciación crítico, c) se elaboran representaciones propias y de los otros sujetos coloniales, d) se negocia la alteridad/subalternidad, e) se historiza/reconstruye ideológicamente el pasado, a la vez que se inscribe el presente, f) se genera conciencia sectorial y se utopiza frente a las posibilidades de la fecundidad americana y g) se construye a sí misma (la función letrada) en una relación ambivalente frente a los mecanismos del discurso colonizador.

Cabe preguntarnos entonces, cuáles son los temas y los problemas explorados por el discurso crítico bibliográfico americano del siglo XVIII, cuáles son la inquietudes teóricas que pretenden ser respondidas por el letrado compilador y cuáles son los núcleos que organizan la historización del pasado cultural. Entre estas preocupaciones podemos mencionar:

1. En el plano de los contextos: a) las polémicas que dieron lugar a la defensa del mundo americano, sumadas a las reformas que afectaron la relación metrópoli/colonia (plano histórico) y b) la necesidad de reivindicar una subjetividad particular emergente criolla y americana (plano ideológico).

2. En el plano del texto: a) los problemas de poética y/o composición de los textos coloniales, b) los modelos y géneros en los que se produjeron los diversos relatos y narrativas sobre/desde América, c) el carácter del sujeto enunciante de los discursos americanos y los públicos lectores/destinatarios.

\footnotetext{
${ }^{15}$ De acuerdo a Luigi Balsamo, en tanto aparato de información de libros y autores, la bibliotheca se relaciona con otros dos registros: el repertorio y el catálogo, los cuales constituirían etapas previas de aquella. El repertorio bibliográfico proporcionaba "la notitia rei literariae (esto es, daba cuenta de la existencia de una determinada obra, sus ediciones impresas y, en algunos casos, también de su contenido)" y el catálogo bibliotecario ofrecía "la notitia librorum, o sea la indagación de que, de determinadas ediciones de ciertas obras, se pueden encontrar ejemplares en un determinado lugar” (Balsamo: 48-49).
} 
3. En el plano del "sistema literario" 16 y del espacio letrado: a) el mayor o menor carácter autonómico/reflejista de la producción cultural literario-historiográfica de América, b) el problema del canon "situado" o la fundación de una canonización alternativa, c) las censuras y los espacios de difusión de la práctica letrada, d) las redes colaborativas letradas generando "sociabilidades letradas"17 y e) la posición ocupada por los autores al interior de la "ciudad letrada" 18.

Lo anterior no quiere decir que algunas de las preocupaciones mencionadas estuviesen ausentes en la práctica catalogadora del siglo XVII, lo que se intenta decir es que la particularidad del discurso crítico bibliográfico del XviII radica en una diferencia cualitativa de método y de objeto respecto de la centuria anterior. Sobre esta cuestión Mabel Moraña indica que "el proyecto historiográfico [catalogador] que en el siglo XVIII define como objeto a las letras americanas surge como paulatina diferenciación del material poético dentro de los voluminosos y heteróclitos acopios, recuentos y catálogos que se componen, ya desde el siglo anterior, como registro de la riqueza cultural continental" (1998c: 300-301), y agrega más adelante que,

${ }^{16}$ Remitimos a la reflexión sobre los "sistemas literarios" que hace Antonio Cornejo Polar, quien desde la crítica literaria y cultural latinoamericana, reconoce la historicidad del término y la necesidad de reactualizarlo como categoría de la historiografía literaria. Cfr. "Los sistemas literarios como categorías históricas. Elementos para una discusión latinoamericana" (1989). Usamos el término por extensión, entendiendo que su uso puede resultar anacrónico para el contexto colonial si no se hace esta aclaración.

${ }^{17}$ Este término proviene de la historia intelectual y se ha utilizado para visibilizar los modos de relación de los diferentes actores culturales al interior de un sistema literario. Por ejemplo, estudia los "espacios" para la formación de públicos lectores (prensa), o de difusión de las ideas (salones, cartas, tertulias), las relaciones de las instituciones con los campos de la cultura (academias, universidades), etc. Al respecto, puede revisarse el estudio El círculo burgués. La sociabilidad en Francia de Maurice Agulhon, publicado en Buenos Aires por Siglo Veintiuno, 2009.

${ }^{18}$ Esta expresión corresponde al título del ya clásico libro de Ángel Rama (1984), editado póstumamente. El trabajo de Rama se enmarca dentro de los estudios de la literatura, la crítica y la cultura latinoamericana; comprende una reflexión sobre el intelectual desde la perspectiva de la modernidad, y abarca, con desigual espesor, desde el siglo XVI al XIx. Entre los temas estudiados se encuentran la función burocrática de los intelectuales, la dirección ideológica de sus discursos y su relación con el poder. Es decir, Rama estudia la articulación entre ciudad real y los "signos". Una actualización de esta categoría es la de "fortaleza docta", estudio de título homólogo de orientación historiográfica, en el que Magdalena Chocano Mena estudia las élites letradas novohispanas. 
asimismo, la historiografía literaria del siglo Xvin se diferencia de la historificación barroca tanto en lo que respecta a la metodología utilizada como a la proyección ideológica de esa práctica cultural. Si metodológicamente se pasa de la recopilación acumulativa y la catalogación a la organización cronológica, con atisbos de periodización y explicitación de los métodos utilizados, ideológicamente se produce el pasaje [...] desde la idea de la riqueza cultural colonial en tanto prueba de la magnificencia del impero, a la confirmación de la fecundidad intelectual americana como evidencia de la productividad criolla, ya diferenciable de y comparable a la metropolitana (301).

En este punto, la autora acota que es necesario puntualizar que este proceso no es irreversible, por cuanto hubo casos como el de Beristáin de Souza en que la práctica bibliográfica sirvió como reforzamiento de la ideología imperial, reaccionando discursivamente ante la insurgencia independentista novohispana (301). Este aspecto no habría sido notado por González-Stephan, quien concebiría un proyecto criollo progresivo, sin retrocesos, cuestión que ha hecho notar la propia Moraña respecto del trabajo de su colega.

Por otra parte, es preciso señalar que desde el punto de vista de los compiladores, los metatextos críticos y los discursos nuncupatorios de los repertorios bibliográficos americanos inscriben las politicas o programas de lectura, ${ }^{19}$ en que los autores modelan un incipiente público lector que, en nuestra opinión, recae en la figura del criollo americano como destinatario último (más allá de los destinatarios directos expresados en cada obra), cuya subjetividad comienza a delinearse paulatinamente desde la primera generación de descendientes de conquistadores y/o beneméritos de los reinos. En muchos casos los prólogos, anteloquias, cartas, censuras y diálogos configuran, ahora desde el punto de vista del lector, una suerte de cartografía de lectura que ilustra al lector americano (y también al europeo) en el modo como se articuló la ciudad letrada, orientándolo en la indagación de su propio patrimonio cultural, a la vez

${ }^{19}$ Por estos conceptos estamos entendiendo la explicitación de pautas, criterios, recomendaciones, sugerencias o lineamientos de lectura, por medio de los cuales los compiladores se aseguraron que el/los lector/es "comprendieran" sus proyectos; en este sentido, orientaban la lectura y explicaban sus "elecciones" conceptuales; por ejemplo, en algunos de los 20 prólogos o anteloquias a su Bibliotheca, Eguiara explica su concepto de mexicanidad que incluye tanto a sus contemporáneos como a los "antiguos mexicanos". 
que muestra el modo como cada bibliógrafo construyó, delineó y asignó los lugares de relevancia a los letrados de la América Septentrional y Meridional, los que desde su perspectiva, representan distintos aspectos de una identidad americana en formación. Es así, entonces, que política de lectura y política identitaria se vinculan de manera estrecha.

Antonio Rubial García en El paraíso de los elegidos (2014) se refiere a dicha conciencia identitaria incipiente en los siguientes términos:

Las constantes referencias al "mexicano imperio", como le llamaban algunos de los más ilustres letrados novohispanos, no era sólo un recurso retórico. Dicha conciencia respondía a una realidad que se manifestaba no sólo en la intensa comunicación que ya se había generado en el territorio como una necesidad administrativa, sino también en la existencia de vastas redes de información que permitían el intercambio de ideas y noticias entre los eruditos de las principales ciudades del virreinato, un poco a la manera de las comunidades de intelectuales que se venían formando en Europa desde el siglo XvI (346).

Finalmente, creemos que en las partes nuncupatorias de estas obras se intenta, además, inscribir al hombre americano en los debates culturales de su tiempo.

A modo de síntesis, podemos señalar que el discurso crítico bibliográfico del siglo XvIII americano se caracteriza por(que):

- Ser elaborado por un agente letrado perteneciente al clero, criollo o mestizo, con acceso a la escritura, es decir, por un sujeto colonial que participa, en distinto modo, de/en la colonialidad. ${ }^{20}$ Es a la vez un sujeto tradicional y moderno, puesto que no renuncia a la fe, ni se aleja totalmente de los modelos escolásticos que concilia con los principios ilustrados y del humanismo jesuítico. Se ubica, por tanto, en la transición que va desde un Barroco en

${ }^{20}$ En su estudio "La colonialidad: la cara oculta de la modernidad", Mignolo indica su tesis sobre la relación modernidad/colonialidad: "La 'modernidad' es una narrativa europea que tiene una cara oculta y más oscura, la colonialidad. En otras palabras, la colonialidad es constitutiva de la modernidad: sin colonialidad no hay modernidad" (2009: par. 2). En este sentido, la colonialidad como ideología de la modernidad supera los límites del período colonial. Cabe señalar que este término es utilizado dentro del conocido "giro decolonial", perspectiva transdisciplinaria que conecta estudios literarios y de la cultura, sociología, antropología, historia cultural y económica, entre otras. 
agotamiento hasta desembocar en una Ilustración que se nutre de los principios racionalistas y de las teorías humanistas.

- Su ejercicio crítico instala la autoridad discursiva del letrado criollo como correlato del proceso de autoafirmación sectorial y de la emergencia de una conciencia sectorial. De paso defiende la riqueza cultural del Nuevo Mundo, y sale al paso de las polémicas sobre la inferioridad americana.

- Autoafirma la diferencia americana criolla en un afán que excede lo meramente laudatorio y apologético, resultando en un ejercicio crítico reivindicativo y en una práctica hermenéutica.

- Mapea el espacio cultural letrado desde la Conquista hasta el presente del catalogador, inscribe un programa de lectura y, de esta manera, comprende un antecedente del pensamiento crítico historiográfico americano.

- Construye una narrativa fundacional que también resultaría en antecedente para la historiografía y la crítica literarias. Es por tanto, una práctica, un archivo y un proyecto criollo - primero- $-\mathrm{y}$ americanista — después.

- Y, permite la instalación de una red de letrados en comunicación activa y colaborativa, evidencia de un proyecto conjunto, en el que el nuevo sujeto colonial (re)piensa desde diferentes posiciones su lugar y su posibilidad de autorrepresentación al interior de la ciudad letrada.

Por último, sirvan estas líneas como una breve mirada de conjunto al discurso crítico bibliográfico del siglo XviII, en las que se intenta dar cuenta de algunos aspectos relevantes en el proceso de conformación de una tradición crítico-bibliográfica que, ya en el XVII, ofrece evidencias de un proyecto letrado criollo y americanista, es decir, los primeros atisbos del pensamiento crítico americano. 
BibliografíA

Primaria Siglo XVIII

Alcedo y Bejarano, Antonio de. Biblioteca Americana. Catálogo de Autores que han escrito de la América en diferentes idiomas y noticia de su vida y patria, años en que vivieron, y obras que escribieron ([1791] 1807). Quito: Publicaciones del Museo Municipal de Arte e Historia. Tomo 1, 1964. Tomo II, 1965.

Beristáin de Souza, José Mariano. Biblioteca Hispanoamericana Septentrional o catálogo y noticias de los literatos que o nacidos o educados, o florecientes en la América Septentrional española, han dado a luz algún escrito o lo han dejado preparado para la prensa, 1521-1850 [1816]. México: Fuente Cultural. Tercera edición. 5 vols., 1947.

Beristáin de Souza, José Mariano. Biblioteca Hispanoamericana Septentrional. México: Instituto de Estudios y Documentos Históricos, A. C. I Universidad Nacional Autónoma de México / Biblioteca del Claustro, 1980. 3 vols. (serie facsimilar).

Eguiara y Eguren, Juan José. Biblioteca Mexicana [1755]. Agustín Millares Carlo, traductor. México: Fondo de Cultura Económica, 1944.

Eguiara y Eguren, Juan José. Prólogos a la Biblioteca Mexicana. Agustín Millares Carlo, traductor. México: Fondo de Cultura Económica, 1944.

Llano Zapata, José Eusebio. Memorias histórico-filosóficas, crítico-apologéticas de la América Meridional [1768]. Perú: Instituto Francés de Estudios Andinos / Pontifica Católica del Perú / Universidad Nacional Mayor de San Marcos, 2005.

Llano Zapata, José Eusebio. Carta persuasiva al señor don Ignacio de Escandón, Colegial, Theologo, que fué en el insigne, y mayor colegio de San Luis de Quito, Thesorero de las Reales Caxas de Cuenca, Regidor y Alcalde ordinario de esta ciudad, y Comandante general de las tropas auxiliares de la de Guayaquil, sobre assunto de escribir la historia literaria de la América Meridional. Reproducida como apéndice en el artículo de Beatriz González-Stephan. "Sujeto criollo / conciencia histórica. La historiografía literaria en el periodo colonial", en José Anadón (ed.). Ruptura de la conciencia hispanoamericana. Época Colonial. España: Fondo de Cultura Económica / University of Notre Dame, 1993: 15-57.

Navarrete, Juan Antonio. Arca de Letras y Teatro Universal I [1780-1811]. Estudio preliminar y edición crítica de Blas Bruni Celli. Caracas: Academia Nacional de la Historia, 1993.

Santa Cruz y Espejo, Francisco Javier Eugenio de. El Nuevo Luciano de Quito o Despertador de los ingenios quiteños en nueve conversaciones eru- 
ditas para el estimulo de la literatura (1779) y La ciencia blancardina (1780).

\section{Bibliografía secundaria}

Anadón, José (ed.) Ruptura de la conciencia hispanoamericana. Época colonial. España: Fondo de Cultura Económica / University of Notre Dame, 1993. Álvarez BARrientos, JoAquín. Los hombres de letras en la España del siglo XVIII: apóstoles y arribistas. Madrid: Castalia, 2006.

Balsamo, Luigi. La bibliografía. Historia de una tradición. Asturias: Trea, 1998.

Castro-Gómez, S. y Grosfoguel, R. El giro decolonial. Reflexiones para una diversidad epistémica más allá del capitalismo global. Bogotá: Siglo del Hombre Editores / Universidad Central / Instituto de Estudios Sociales Contemporáneos / Pontificia Universidad Javeriana / Instituto Pensar, 2007.

Cevallos, Francisco Javier. "Imitatio, aemulatio, elocutio: hacia una tipología de las poéticas de la época colonial”, en Revista Iberoamericana. Literatura colonial II. Sujeto colonial y discurso barroco, núm. 172-173 (jul.-dic. 1995): 501-515.

Chocano Mena, Magdalena. La fortaleza docta: Elite letrada y dominación colonial social en el México colonial. Siglos XV-XVII. Barcelona: Bellaterra, 2000.

De la Torre Villar, Ernesto. "Las Bibliotecas de Eguiara y Beristáin: Valor y diferencias", en Juan José Eguiara y Eguren. Biblioteca Mexicana. México: Universidad Nacional Autónoma de México, 1986: CCXCVIICCCXI.

Gerbi, Antonello. La disputa del Nuevo Mundo. Historia de una polémica. 1750-1900. Trad. Antonio Alatorre. México: Fondo de Cultura Económica, 1990. [Segunda edición en español, corregida y aumentada, 1982.]

Góngora, Mario. "Estudios sobre el Galicanismo y la 'ilustración católica' en América española”, en Revista Chilena de Historia y Geografía. Santiago, núm. 125 (1957): 96-151.

Góngora, Mario. "Aspectos de la Ilustración católica en el pensamiento y la vida eclesiástica chilena (1770-1814)”, en Historia. Santiago, núm. 8 (1969): 43-73.

Góngora, Mario. Estudios sobre la historia colonial de Hispanoamérica. Santiago: Universitaria, 1998.

GonZÁlez-Stephan, BeATriz. Fundaciones: canon, historia y cultura nacional. La historiografía literaria del liberalismo hispanoamericano del siglo XIX [1997]. Madrid: Iberoamericana-Vervuert, 2002. 
GonzÁlez-Stephan, Beatriz. "Sujeto criollo / conciencia histórica. La historiografía literaria en el periodo colonial", en José Anadón (ed.). Ruptura de la conciencia hispanoamericana. Época colonial. Espańa: Fondo de Cultura Económica / University of Notre Dame, 1993: 5-57.

Hachim, Luis. "Teorías hegemónicas y pensamiento excluido. El caso de Beristáin de Souza" (1999).

Hachim, Luis. Tres estudios sobre el pensamiento crítico de la ilustración americana. Murcia: Universidad de Alicante / Universidad de Santiago de Chile, 2000.

Hachim, Luis. "La carta a los espańoles americanos (1791) del Abate Viscardo y la tradición crítica en América" (2000a), "Políticas de identidad y pensamiento americano en una Biblioteca del siglo xviII" (2000b) y "La Ilustración en Eugenio de Santa Cruz y Espejo" (2000c), en Cuadernos de América sin nombre, núm. 2, dirigido por Carlos Rovira.

Haснім, Luis. "De León Pinelo a Beristáin: Ensayo sobre la tradición de los repertorios literarios latinoamericanos", en Revista Chilena de Literatura. Santiago, núm. 59 (2001): 139-150.

Hachim, Luis. Summa de libros y autores del período colonial. La biblioteca Hispanoamericana de José Mariano Beristáin de Souza. Valparaíso: Editorial Puntángeles / Ediciones de la Universidad de Playa Ancha, 2012.

Higgins, Antony. "La 'Bibliotheca Mexicana': Hacia una poética de la legitimidad criolla", en Revista de Crítica Literaria Latinoamericana, año 22, núm. 43/44 (1996): 77-87.

Higgins, Antony. "Sobre la construcción del archivo criollo: el Aprilis dialogus y el proyecto de la Bibliotheca mexicana", en Revista Iberoamericana. Literatura colonial II. Sujeto colonial y discurso barroco, núm. 172-173 (jul.-dic. 1995): 573-589.

Jáuregui, C. y Moraña, M. (eds.). Colonialidad y crítica en América Latina. Bases para un debate. Puebla: Universidad de las Américas, 2007.

Mignolo, Walter. "El metatexto historiográfico y la historiografía indiana", en $M L N$, vol. 96, núm. 2, Hispanic Issue (Mar., 1981): 358402.

Mignolo, Walter. "La colonialidad: la cara oculta de la modernidad", en Sabine Breitwieser (coord.). Modernologias: artistas contemporáneos investigan la modernidad y el modernismo. Barcelona: Museo de Arte Contemporáneo de Barcelona, 2009: 39-49. Artículo disponible en: <www.macba.es/PDFs/walter_mignolo_modernologies_cas.pdf $>$ Fecha de consulta: 13/08/2015.

Millares Carlo, Agustín. "Don José Mariano Beristáin de Souza y su Biblioteca Hispanoamericana Septentrional", en Interamerican Review of Bibliography. Washington, D. C., vol. XVI, núm. 1: 20-57. 
Moraña, Mabel. Viaje al silencio. Exploraciones del discurso barroco. México: Universidad Nacional Autónoma de México. Facultad de Filosofía y Letras, 1998.

Moraña, Mabel. "Para una relectura del Barroco: problemas críticos e historiográficos”, en Viaje al silencio. Exploraciones del discurso barroco. México: Universidad Nacional Autónoma de México. Facultad de Filosofía y Letras, 1998a: 49-61.

Moraña, Mabel. "Formación del pensamiento crítico-literario en Hispanoamérica: época colonial”, en Viaje al silencio. Exploraciones del discurso barroco. México: Universidad Nacional Autónoma de México. Facultad de Filosofía y Letras, 1998b: 279-292.

Moraña, Mabel. "Fundación del canon: hacia una poética de la historia en la Hispanoamérica colonial”, en Viaje al silencio. Exploraciones del discurso barroco. México: Universidad Nacional Autónoma de México. Facultad de Filosofía y Letras, 1998c: 293-327.

Moraña, Mabel. "Apologías y defensas: discursos de la marginalidad en el Barroco Hispanoamericano", en Viaje al silencio. Exploraciones del discurso barroco. México: Universidad Nacional Autónoma de México. Facultad de Filosofía y Letras, 1998d: 259-278.

Moraña, Mabel. Crítica impura. Estudios de literatura y cultura latinoamericanos. Madrid: Iberoamericana-Vervuert, 2004.

Osorio, Nelson. "Formación del pensamiento crítico literario en la Colonia”, en José Anadón (ed.). Ruptura de la conciencia hispanoamericana. Época colonial. España: Fondo de Cultura Económica / University of Notre Dame, 1993: 59-76.

Peralta Ruiz, Víctor. "De rústicos a civilizados. El concepto de civilidad en tres historias de la América Meridional del siglo XVIII", en Histórica, XXX, núm. 1 (2006): 137-163.

Rubial García, Antonio. El paraiso de los elegidos: Una lectura de la historia cultural de la Nueva España (1521-1804). México: Fondo de Cultura Económica / Universidad Nacional Autónoma de México. Facultad de Filosofía y Letras, reimpresión de 2014.

Torre Villar, Ernesto de la. "Bibliógrafo José Mariano Beristáin y Souza (1756-1817)", en Tempus. Revista de Historia de la Facultad de Filosofía y Letras, Universidad Nacional Autónoma de México, núm. 2 (invierno de 1993-1994).

Vitulli, J. y Solodkow, D. (comps.). Poéticas de lo criollo. La transformación del concepto "criollo" en las letras hispanoamericanas (siglo XVI al XIX). Buenos Aires: Corregidor, 2009. 